\title{
Epiphysiolysis of the hip
}

INSERM

\section{Source}

INSERM. (1999). Orphanet: an online rare disease and orphan drug data base.

Epiphysiolysis of the hip. ORPHA:399329

Epiphysiolysis of the hip is a rare osteonecrosis disorder characterized by unilateral or bilateral disruption of the capital femoral physis with varying degrees of posterior epiphysis translation and simultaneous anterior metaphysis displacement. Patients typically present in pre-adolescence/adolescence with pain of variable intensity in varying locations (hip, groin, thigh, knee). 